\title{
Exportin Crm1 is important for Swi6 nuclear shuttling and MBF transcription activation in Saccharomyces cerevisiae
}

\author{
Kenneth D. Belanger ${ }^{1 *}$, William T. Yewdell ${ }^{1,2}$, Matthew F. Barber ${ }^{1,3}$, Amy N. Russo ${ }^{1,4}$, Mark A. Pettit ${ }^{1,5}$, \\ Emily K. Damuth ${ }^{1,6}$, Naveen Hussain ${ }^{1,7}$, Susan J. Geier ${ }^{1,8}$ and Karyn G. Belanger ${ }^{1,9}$
}

\begin{abstract}
Background: Swi6 acts as a transcription factor in budding yeast, functioning in two different heterodimeric complexes, SBF and MBF, that activate the expression of distinct but overlapping sets of genes. Swi6 undergoes regulated changes in nucleocytoplasmic localization throughout the cell cycle that correlate with changes in gene expression. This study investigates how nucleocytoplasmic transport by multiple transport factors may influence specific Swi6 activities.

Results: Here we show that the exportin Crm1 is important for Swi6 nuclear export and activity. Loss of a putative $\mathrm{Crm} 1 \mathrm{NES}$ or inhibition of $\mathrm{Crm} 1$ activity results in changes in nucleocytoplasmic Swi6 localization. Alteration of the Crm1 NES in Swi6 results in decreased MBF-mediated gene expression, but does not affect SBF reporter expression, suggesting that export of Swi6 by Crm 1 regulates a subset of Swi6 transcription activation activity. Finally, alteration of the putative Crm1 NES in Swi6 results in cells that are larger than wild type, and this increase in cell size is exacerbated by deletion of Msn5.

Conclusions: These data provide evidence that Swi6 has at least two different exportins, Crm1 and Msn5, each of which interacts with a distinct nuclear export signal. We identify a putative nuclear export signal for Crm1 within Swi6, and observe that export by Crm1 or Msn5 independently influences Swi6-regulated expression of a different subset of Swi6-controlled genes. These findings provide new insights into the complex regulation of Swi6 transcription activation activity and the role of nucleocytoplasmic shuttling in regulated gene expression.
\end{abstract}

Keywords: Karyopherin, Exportin, Nucleocytoplasmic transport, Swi6, Nuclear shuttling

\section{Background}

Cell cycle progression is a highly regulated process in all cells. In eukaryotes, cells become committed to progression through the cell cycle during the late $G_{1}$ phase at a point termed the restriction point, also referred to as START in yeast $[1,2]$. In Saccharomyces cerevisiae, progression through START correlates with specific cellular

\footnotetext{
*Correspondence: kbelanger@colgate.edu

1 Department of Biology, Colgate University, Hamilton, NY, USA

Full list of author information is available at the end of the article
}

characteristics such as appropriate cell size and rate of protein synthesis, as well as the transcription of a certain subset of genes, including about 200 of which undergo a peak in expression at this point [3-7]. These genes function in a variety of roles, including mating type switching, DNA replication, budding, cell wall synthesis, and spindle pole body duplication (see [8-10]). All of these molecular events are critical to proper progression through the cell cycle and depend on specific transcriptional activation at a precise stage of the cycle $[8,11]$. This activation is initiated by the $\mathrm{Cln} 3 / \mathrm{Cdc} 28$ cyclin/cyclin-dependent kinase 
(Cdk) complex, which stimulate an intricately timed sequence of protein modifications and gene expression changes that commit the cell to START $[12,13]$.

Of the hundreds of yeast genes that undergo changes in expression during the $\mathrm{G}_{1}-\mathrm{S}$ transition, the vast majority fall at least partially under the regulation of two heterodimeric transcription factors, MBF and SBF [14]. MBF (MluI cell-cycle box binding factor) and SBF (Swi4/6 cell-cycle box binding factor) are both composed of Swi6 plus one other protein, Mbp1 and Swi4, respectively ([15, 16], reviewed in [17]). In their respective complexes with Swi6, Swi4 and Mbp1 function as the sequence-specific DNA binding component, while Swi6 itself functions as the transcription activating component $[16,18,19]$. SBF and MBF regulate the expression of distinct but overlapping sets of genes with MBF primarily controlling genes involved in DNA replication and repair while SBF upregulates genes involved in cell growth, cell wall organization, and the timing of progression through START ([14, 20]; reviewed in [21]).

In eukaryotic cells, progression through the cell cycle is dependent on the precise temporal control of distinct transcriptional programs. One mechanism that contributes to this control is the regulated nucleocytoplasmic localization of specific proteins. Proteins entering the nucleus either contain a nuclear localization signal (NLS) within their polypeptide sequence or associate with an NLS-containing protein (reviewed in [22, 23]). The NLS is then recognized by an importin member of the Ranbinding karyopherin protein family of nuclear transport factors (NTFs), which chaperones the NLS-containing proteins through the nuclear pore complexes (NPCs) that perforate the nuclear envelope $[24,25]$. Once in the nucleus, the importin releases its cargo protein so that the cargo is free to perform its intranuclear function $[26,27]$. Many proteins imported into the nucleus also undergo nuclear export [28-30], resulting in the regulated nucleocytoplasmic shuttling of these polypeptides. Actively exported proteins contain a nuclear export signal (NES) that is recognized by an exportin member of the karyopherin NTF family, which associates with the NES and transports the cargo protein out of the nucleus through the NPCs $[31,32]$. Importantly, there are multiple types of karyopherin proteins (14 in yeast; approximately 20 in mammals [33];) and different karyopherins function as importins or exportins for specific subsets of proteins based on the NLSs and NESs present within those proteins, thus allowing for regulation of nucleocytoplasmic localization of specific proteins or protein families.

The activity of many transcription factors is regulated in part by control of their intracellular localization. In mammalian cells, the transcriptional activation activity of $\mathrm{NF \kappa B}$ is largely determined by the cytosolic regulator I $\mathrm{B}$ which, when present, binds $\mathrm{NF}_{\kappa} \mathrm{B}$ in a manner that blocks its NLS and thus prevents it from entering the nucleus and activating transcription. Upon degradation of IkB after signal-activated phosphorylation, the $\mathrm{NF} K \mathrm{~B}$ NLS is exposed, associates with its importin protein, and rapidly enters the nucleus [34]. This nuclear entry results in activation of transcription of $\mathrm{NF} \mathrm{KB}$ responsive genes [35]. Nucleocytoplasmic localization regulates a variety of other important transcription factors, including SMAD, $\beta$-catenin, p53, and STAT proteins [36-39].

The yeast Swi6 transcription factor undergoes dynamic changes in intracellular localization, as it is primarily nuclear under some conditions and cytoplasmic under others [40-42]. Two different importins, the Kap60/ Kap95 (Importin- $\alpha / \beta$ ) heterodimer and the monomeric Kap120 $\beta$-importin, bind to distinct NLS sequences within Swi6 to mediate its nuclear import under different conditions [40,43]. Swi6 rapidly accumulates in the nucleus in late mitosis and remains primarily nuclear until the end of G1, at which time it becomes cytosolic [41]. The import during G1 occurs via the Kap60/Kap95 importin- $\alpha / \beta$ complex and is inhibited by $\mathrm{Clb} 6 / \mathrm{Cdc} 28$ mediated phosphorylation of Ser160 adjacent to the classical NLS (cNLS) recognized by Kap60/Kap95 [43, 44]. Swi6 nuclear import also rapidly occurs in response to cell wall stress, in this case being mediated by Kap120 and negatively regulated by Mpk1-mediated phosphorylation of Ser238 adjacent to the Kap120-recognized NLS [40]. In both cases, phosphorylation correlates with a rapid loss of nuclear Swi6 and changes in Swi6-mediated gene expression [40, 41, 43, 44].

Regulation of Swi6 nuclear export also appears to be important for determining its transcriptional activity. A deletion of Msn5, a yeast karyopherin with exportin function, results in Swi6 primarily localized to the nucleus throughout the entire cell cycle, and leads to decreased expression of SBF-responsive but not MBF-responsive genes [45]. Interestingly, depletion of Msn5 during one round of the cell cycle results in a lack of Swi6 binding to an SBF-responsive promoter in the following G1-S phase, suggesting that the nuclear export of Swi6 is necessary for proper SBF function in the succeeding cell cycle [45]. Thus, regulation of both nuclear import and export is critical for proper Swi6-mediated gene expression.

Here we provide evidence for the function of an additional exportin, $\mathrm{Crm} 1 / \mathrm{Xpo1}$, in regulating the intracellular localization of Swi6 in Saccharomyces cerevisiae in a cell cycle dependent pattern and identify a putative Crm1 nuclear export signal (NES) within Swi6. We also provide evidence that both Msn5 and Crm1/Xpo1 are critical for normal Swi6 function, and that regulated export by 
each differentially impacts Swi6 transcription activation activity.

\section{Results}

Swi6-GFP undergoes nucleocytoplasmic shuttling

Swi6 protein is localized primarily in the nucleus during G1 and S-phase of the cell cycle, when it functions as an active transcription factor [14, 41]. However, this nuclear accumulation decreases during G2 and M-phase and the protein becomes largely cytoplasmic [41]. While these observations suggest that Swi6 protein shuttles in and out of the nucleus in a cell cycle-dependent manner, such changes in localization could also be observed due to changes in nuclear import rates combined with localized Swi6 protein degradation. In order to confirm that Swi6-GFP shuttles in and out of the nucleus, we performed a heterokaryon shuttling assay [46]. Galactosedependent expression of Swi6-GFP was induced in a haploid yeast strain until Swi6-GFP was observed in the nucleus, and then repressed by incubating in glucose. The cells were then mated with a yeast strain containing a kar1-1 allele that prevents karyogamy after zygote formation [47]. The resulting heterokaryon has Swi6-GFP in one nucleus and lacks fluorescence in the other at the time of cell fusion. Because new Swi6-GFP expression is repressed, the only way for the kar1-1 mutant nucleus to accumulate significant fluorescence is via Swi6-GFP protein export or diffusion from the wild-type nucleus and re-import into the kar1-1 nucleus. Thus, if only one nucleus exhibits fluorescence, Swi6-GFP does not shuttle. In contrast, if GFP is present in both nuclei, Swi6 is capable of nucleocytoplasmic shuttling. We observe that in every heterokaryon generated $(n=20)$, Swi6-GFP is found in both nuclei (Fig. 1). As controls for this assay, we observe that the shuttling tRNA export factor Cca1-GFP [46] is present in both nuclei in heterokaryons, while the non-shuttling histone $\mathrm{H} 2 \mathrm{~B}$ protein [49] is retained only within one nucleus. While previous experiments showing changes in intracellular Swi6 localization had suggested that the protein underwent bidirectional nucleocytoplasmic transport $[41,45]$, our data indicate conclusively that Swi6-GFP truly is a "shuttling" protein that undergoes both nuclear import and export under steady-state conditions.

\section{Swi6 residues 250-258 are important for optimal nuclear export}

While the redistribution of Swi6 between the nucleus and cytosol has been identified previously as necessary for changes in Swi6 activity throughout the cell cycle and multiple NLSs and importins have been identified that contribute to nuclear import [40,41,43, 45], the region(s) of Swi6 necessary for nuclear export remain unknown. To identify sequences important for Swi6 export, we generated Swi6 truncation mutants fused with GFP, expressed each in wild type yeast, and performed

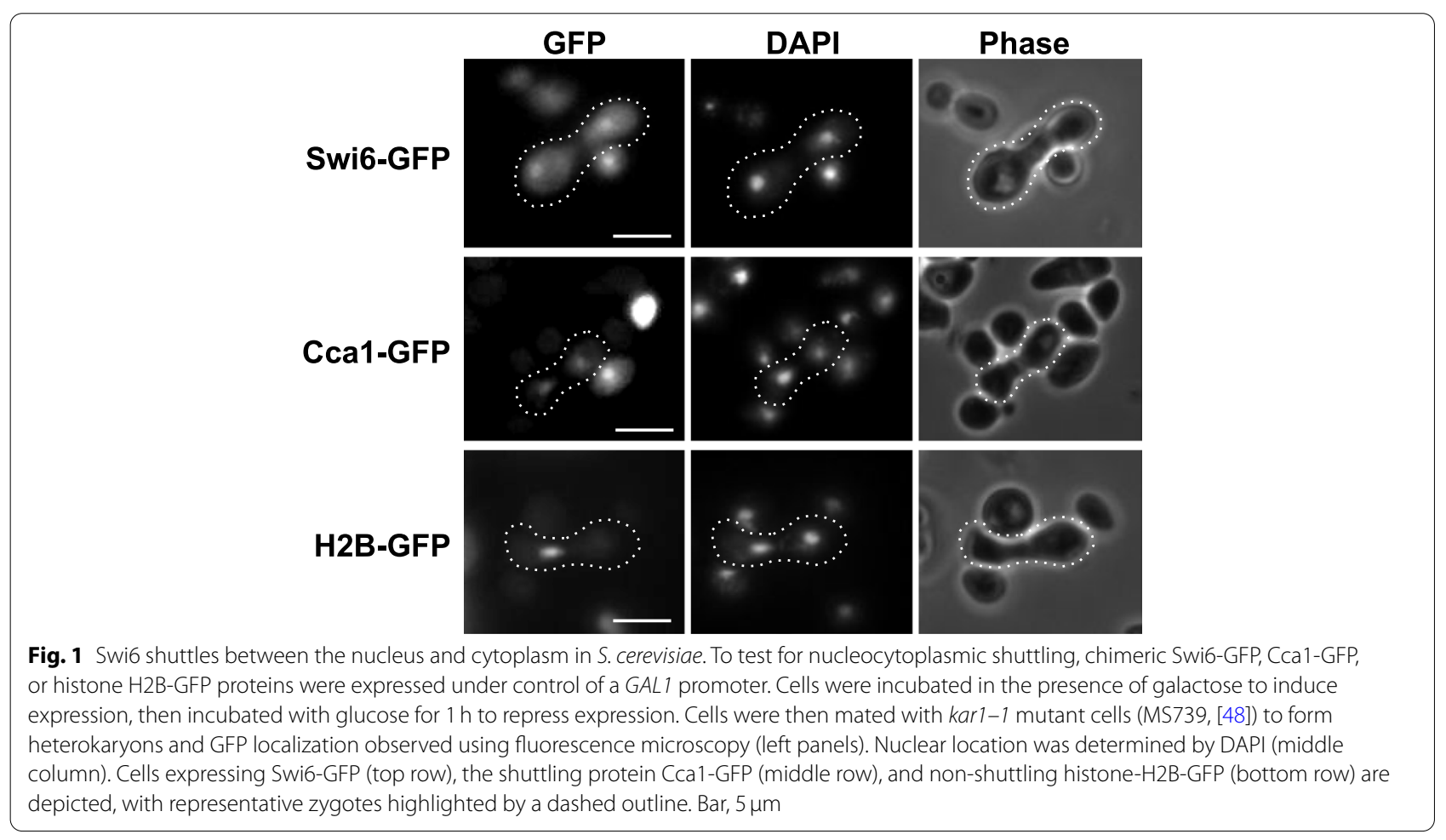


fluorescence microscopy on synchronously growing populations of cells (Fig. 2). Based on cell and nuclear morphology (Fig. 2B), cells expressing all three Swi6 mutants are in S-phase by $80 \mathrm{~min}$ after release from $\alpha$-factor and have entered late mitosis, with large buds and migrating nuclei, by $120 \mathrm{~min}$ after release. Both full-length $\left(\right.$ Swi6 $\left.6^{1-803}[41]\right)$ and truncated (Swi6 ${ }^{1-273}$-GFP; Fig. 2B, C) exhibit reduced nuclear localization shortly after release from $\alpha$-factor, with nearly completely cytoplasmic fluorescence $80 \mathrm{~min}$ after release, and return to the nucleus by $120 \mathrm{~min}$. In contrast, the more severely truncated version (Swi $6^{1-181}$-GFP) is retained in the nucleus throughout the cell cycle (Fig. 2B, C). Thus, the region of Swi6 between amino acids 181 and 273 is important for changes in nuclear Swi6 concentration during G1/S.

Proteins that are exported from the nucleus by exportin Crm1/Xpo1 typically contain a leucine-rich nuclear export signal (NES) or associate with another NES-containing polypeptide $[25,28,30,51]$. Close inspection of the amino acid sequence found between Swi6 residues 181 and 273 revealed a leucine-rich region from amino acids 250-258 that aligns closely with NES sequences from other Crm1 export cargoes (Fig. 2D). In addition, the leucine-rich region spanning amino acids $250-258$ is highly conserved across hemiascomycetes, with relatively rare amino acid changes within the putative NES relative to areas flanking the leucine-rich sequence (Fig. 2E).

To determine if this putative Crm1 NES is necessary for normal Swi6 localization throughout the cell cycle, we mutagenized Swi6 ${ }^{1-273}$-GFP so that leucines at amino acids 250, 254, 257, and 258 were all altered to alanines (Swi6 $6^{1-273} \Delta$ NES-GFP). Cells expressing Swi $6^{1-273}$-GFP, Swi ${ }^{1-181}$-GFP, and $\mathrm{Swi}^{1-273} \Delta \mathrm{NES}-$ GFP were then treated with $\alpha$-factor and localization observed for synchronous populations of cells. Similar to the Swi ${ }^{1-181}$-GFP truncation, Swi $6^{1-273} \Delta$ NES-GFP remained predominantly nuclear as cells progressed from
G1 into S-phase, although some cytoplasmic redistribution was observed (Fig. 2B). To further analyze these changes, we used our GFP-tagged proteins to examine the percentage of cells expressing primarily nuclear fluorescence [52-54] at 20-min intervals after release from $\alpha$-factor (Fig. 2C). Sixty min after $\alpha$-factor release, fewer than $10 \%$ of cells expressing Swi $6^{1-273}$-GFP exhibited nuclear fluorescence, compared to over $45 \%$ of cells expressing Swi6 ${ }^{1-181}$-GFP, confirming the increase in nuclear retention of Swi6 lacking residues 181-273. Interestingly, cells expressing the $\mathrm{Swi}^{1-273} \Delta \mathrm{NES}-\mathrm{GFP}$ exhibited an intermediate level of Swi6 export, with $26 \%$ of cells exhibiting primarily nuclear fluorescence $60 \mathrm{~min}$ after $\alpha$-factor release. These data suggest that the leucine residues found within the predicted NES sequence in Swi6 are important but not essential for Swi6 nuclear export.

\section{Crm1 is an exportin for Swi6}

The exportin $\mathrm{Crm} 1 / \mathrm{XpoI}$ associates directly with leucine-rich NES sequences on cargo proteins in the presence of Ran-GTP in order to facilitate the translocation of cargoes out of the nucleus $[31,51]$. If the leucine-rich domain found within Swi6 functions as an NES for Crm1, the Swi6 and Crm1 proteins should physically associate in the presence of Ran-GTP. To determine if there is a physical interaction between Crm1 and Swi6, we tested for protein-protein interactions in vivo using the yeast two-hybrid system [55], which provides endogenous nuclear Ran-GTP to allow assembly of heterotrimeric NES/exportin/Ran complexes [31, 51]. Two-hybrid plasmids were generated that express full-length Swi6 in-frame with a GAL4 transcription activation domain (Swi6-AD) and full-length Crm1 in-frame with a GAL4 DNA binding domain (Crm1-BD). These plasmids were then introduced into cells either in combination or with an empty vector control containing only a GAL4 DNA

\footnotetext{
(See figure on next page.)

Fig. 2 Swi6 contains a leucine-rich domain that is necessary for efficient nuclear export. (A) Cartoon diagram depicting truncation mutants lacking amino acids 274-803 (Swi6 $6^{1-273}$-GFP) and 182-803 (Swi6 ${ }^{1-181}$-GFP) from the carboxy-terminus of Swi6 fused with GFP. Sites of NLSs interacting with Kap95 [43, 44, 50] and with Kap120 [40] are shown, along with the location of the Crm1-NES investigated in this study. The NES sequence in Swi6 recognized by Msn5 has not been determined and thus is not depicted here. (B) Swi6 nuclear export decreases upon deletion of amino acids 182-274 or mutagenesis of leucines to alanines within the NES-like sequence at amino acids 250-258. Cells expressing Swi6 ${ }^{1-273}$-GFP (left), Swi6 ${ }^{1-}$ ${ }^{181}$-GFP (middle), or Swi6 ${ }^{1-273} \triangle N E S$-GFP (right) were arrested with a-factor, then released from arrest to observe Swi6 localization in synchronous cell populations. Cells expressing the Swi6-GFP fusions were observed by direct fluorescence (GFP) and phase-contrast (Phase) microscopy at the timepoints indicated after release from arrest. Bar, $5 \mu \mathrm{m}$. (C) Nuclear export of Swi $6^{1-273} \triangle N E S$-GFP is intermediate between Swi6 $6^{1-273}$-GFP and Swi6 ${ }^{1-181}$-GFP. A plasmid encoding Swi6 amino acids 1-273 fused with GFP was subjected to site directed mutagenesis so that codons 250, 254, 257, and 258 encode alanines rather than leucines, generating Swi $6^{1-273} \triangle N E S$-GFP. Plasmids expressing Swi $6^{1-273} \Delta N E S-G F P$, Swi $6^{1-273}$-GFP, and Swi6 ${ }^{1-181}$-GFP were expressed in synchronized cells and the percent of cells with nuclear GFP fluorescence was determined for each Swi6 fusion at 20-min intervals after release from a-factor. Cells were synchronized as in (B) and observed by direct fluorescence (GFP) and phase-contrast (phase) microscopy at the time intervals indicated after release from a-factor arrest. Error bars depict s.e.m. from at least three experiments. (D) Alignment of Swi6 amino acids 250-258 with leucine-rich nuclear export signals (NESs) from other shuttling proteins. Leucine residues are underlined. (E) Alignment of Saccharomyces cerevisiae Swi6 leucine-rich sequence and flanking residues with homologous regions from fungi Saccharomyces paradoxus, Saccharomyces pastorianus, Zygosaccharomyces bailii, Candida glabrata, and Kluyveromyces lactis. Leucine-rich Crm1-NES-like sequences aligning with amino acids 250-258 from S. cerevisiae are highlighted in yellow. Amino acids that differ from S. cerevisiae Swi6 are red
} 
A

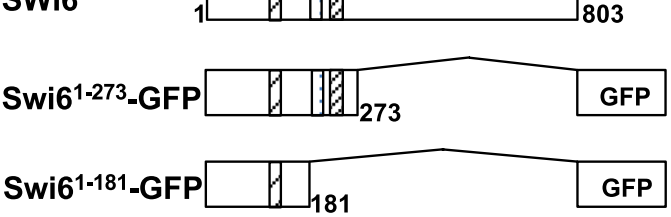

B
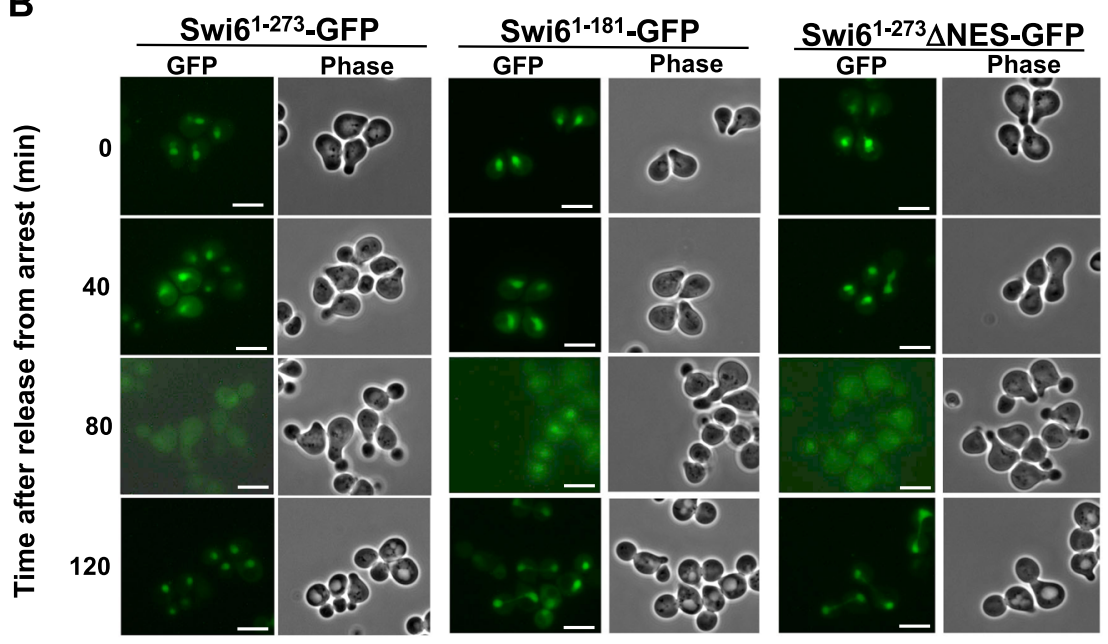

C

D

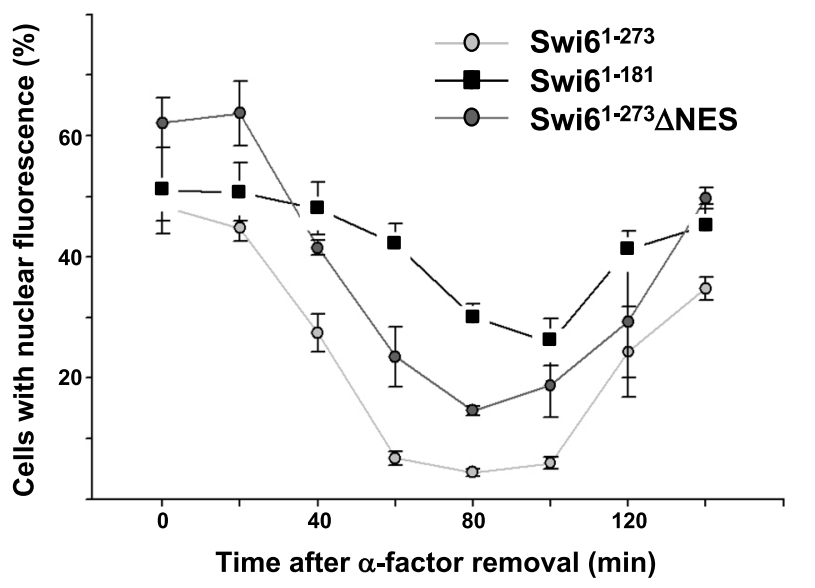

Protein Crm1 NES

c-AbI LESNLRELQI

Rev LPPP-LERLTL

TFIIIA LPPV-LENLTL

Cyclin B1 LCQAFSDVLI

RanBP1 VAIIKLEALS므

Swi6 LEAFLQRL-L

\section{E}

S. cerevisiae

241

242

250

S. pastorianus

VSDNNQRMKLEAFLQRLLFPEVQDL--_-_-_---_----SSTSHDTHHM

284

C. glabrata 277 V-DNDQKLKLETFLQRLLFPEAHESPSKLGSKNGNTNPSH-----------T 316

K. lactis 225 SNSNDERAKLETLLQRILFPET----TNLNV------A-EGYPSVNLTQQV 265

Fig. 2 (See legend on previous page.) 


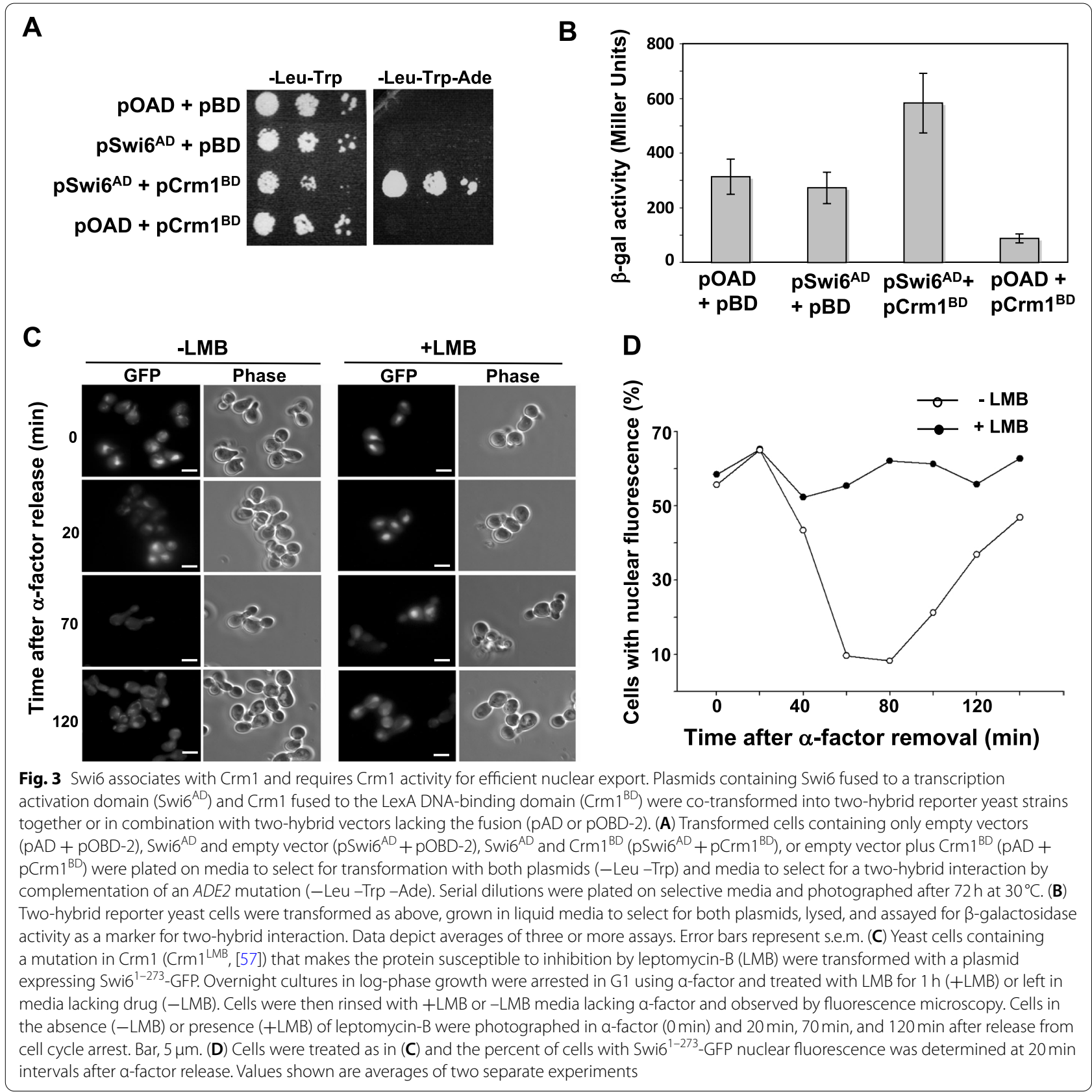

binding domain (pOBD-2) or transcription activation domain (pOAD; [56]). Cells were then assayed for Crm1Swi6 interactions using two different reporter genes (Fig. 3). We first used an $A D E 2$ two-hybrid reporter, which allows cells to grow on media lacking adenine if Swi6-AD and Crm1-BD interact in vivo. Cells expressing both Swi6-AD and Crm1-BD activated the $A D E 2$ reporter and exhibited robust growth on the -Ade selective media. In contrast, cells expressing any combination of either Swi6-AD or Crm1-BD with an empty vector did not grow on -Ade media. These data provide evidence that Swi6 and Crm1 physically interact in vivo, although they do not indicate whether the interaction is direct or indirect. Interestingly, the co-expression of Swi6-AD and Crm1-BD reduced cell growth on non-selective media (Fig. 3A, left plate), while independent expression of either allowed for robust growth, providing additional genetic evidence for an interaction between the chimeric Swi6 and Crm1 proteins. 
To confirm this two-hybrid interaction between Swi6 and Crm1, we performed a quantitative assay for expression of an interaction-dependent LacZ reporter. Using the same combinations of two-hybrid plasmids described above, we lysed cells and assayed for LacZ expression using a colorimetric assay for $\beta$-galactosidase activity (Fig. 3B). Yeast cells containing both the Crm1-BD and Swi6-AD plasmids had a significantly higher expression of the LacZ reporter than cells containing the Crm1-BD and empty vector control (Tukey multiple comparison of means, $p=0.005)$. Crm1-BD/Swi6-AD co-expression also resulted in more than two times the $\beta$-galactosidase activity of cells expressing just Swi6-AD or empty vector, although variation between samples limited statistical significance ( $p=0.1$ and $p=0.07$, respectively). These data provide further evidence that Swi6 and Crm1 physically associate, consistent with a role for Crm1 in Swi6 nuclear export.

To test if the exportin Crm1 is essential for Swi6 nuclear export, we introduced Swi6 $6^{1-273}$-GFP into yeast cells expressing a leptomycin $\mathrm{B}$ (LMB)-sensitive form of $\mathrm{Crm} 1\left(\mathrm{Crm} 1^{\mathrm{LMB}}\right.$; [57]) as their only source of $\mathrm{Crm} 1$ protein. LMB associates directly with $\mathrm{Crm} 1^{\mathrm{LMB}}$, blocking Crm1 interaction with NESs and thus inhibiting nuclear export of proteins containing a Crm1 NES, but not affecting the nucleocytoplasmic shuttling of proteins transiting the NPC independently of Crm1 $[57,58]$. $\mathrm{Crm} 1^{\mathrm{LMB}}$ cells were treated with $\alpha$-factor, incubated with LMB, then released from cell cycle arrest. Swi6 ${ }^{1-273}$-GFP localization was observed over time by fluorescence microscopy (Fig. 3C, D). While Swi6 ${ }^{1-273}$-GFP, like full-length Swi6 [41], is normally nuclear during G1 and S-phases and cytoplasmic during $\mathrm{G} 2$ and $\mathrm{M}, \mathrm{Crm} 1^{\mathrm{LMB}}$ cells treated with LMB retained Swi ${ }^{1-273}$-GFP in the nucleus after release from treatment with $\alpha$-factor. Thus, Crm 1 activity is necessary for nucleocytoplasmic changes in Swi6 localization. These data, along with evidence from Queralt and Igual [45], provide evidence that Swi6 has two exportins, Crm1 and Msn5, that influence its coordinated, cell cycle-dependent export from the nucleus.

\section{Swi6 export by $\mathrm{Crm} 1$ is important for MBF activity}

To determine if Swi6 export by each of the two exportins, Msn5 and Crm1, functions in distinct Swi6 activities, we investigated SBF and MBF activation in the absence of Crm1-mediated export. Nuclear export of Swi6 by Msn5 has been shown to be important for SBF activity [45]. Thus, we first sought to determine if Crm1-mediated export of Swi6 was also necessary for SBF activation. If Swi6 export by Crm 1 is critical for SBF activity, then Swi6 harboring a Crm1-specific NES mutation should reduce expression of SBF targets. To determine if alteration of the Swi6 Crm1-NES sequence affects transcription activation by SBF, we altered a plasmid expressing wild type SWI6 so that each leucine in the NES between residues 250 and 258 was converted to an alanine, making full-length Swi6 $\triangle$ NES. We then expressed full length Swi6 and Swi6 $\triangle$ NES in cells lacking endogenous SWI6 and containing a chimeric reporter construct with an SBF-responsive promoter element upstream of a LacZ reporter [4]. Activation of gene expression for the SBFLacZ reporter was subsequently assayed by measuring $\beta$-galactosidase activity in each strain (Fig. 4A). We observe that SBF activity is not significantly different between cells expressing SWI6 and swi6 $N$ NES $(p=0.95)$, while a complete deletion of SWI6 (swi6A) results in a statistically significant $(p<0.005) 10$-fold reduction of SBF reporter activity.

Given that Swi6 participates in both SBF and MBF activity, we sought to determine whether the $\triangle \mathrm{NES}$ mutation also affects trans-activation by MBF. To this end, we expressed SWI6 and swi6 $2 N E S$ in cells containing an MBF-LacZ reporter and $\beta$-galactosidase activity was measured for each (Fig. 4B). MBF activity undergoes a decrease (2.5-fold) in cells expressing swi6 $\triangle N E S$ as their only source of Swi6 when compared to Swi6expressing cells. However, MBF reporter activity remains higher in the presence of swi6 $\triangle N E S$ than in swi6 $\Delta$ cells lacking Swi6 protein. While a pairwise comparison of the difference between MBF reporter expression in the swi6 $\triangle N E S$ strain and that in either SWI6 or swi6 cells is not statistically significant to a $p$-value of less than 0.05 , analysis by ANOVA indicates statistically significant overall variation in MBF expression among the three strains $(p<0.01)$. This trend suggests that the elimination of the Crm1-dependent NES from Swi6 reduces but does not eliminate the ability of Swi6 to contribute to MBF activity. These data suggest that $\mathrm{Crm} 1$-mediated export of Swi6 is important for the transcription activation function of MBF, but not of SBF, providing evidence that export mediated by $\mathrm{Crm} 1$ and Msn 5 are each important for unique aspects of Swi6 function.

\section{Decreased Swi6 export results in increased cell size}

Yeast cells lacking Swi6 exhibit an increased cell size phenotype [7]. To test whether the Crm1 NES is necessary for Swi6 function in regulating yeast cell size, we expressed the swi6 $\triangle N E S$ mutant in cells lacking endogenous SWI6 and measured asynchronous cultures of log-phase cells for average cell diameter (Fig. 5). As controls, we expressed wild-type SWI6 or transformed cells with an empty plasmid control vector. Expressing wild-type SWI6 in swi6 $\Delta$ deleted cells produced nearly normal-sized cells ( $7.69 \mu \mathrm{m}$ average diameter; $\mathrm{SE}=0.22 \mu \mathrm{m})$ compared to wild-type $(7.03 \mu \mathrm{m} ; \mathrm{SE}=0.07 \mu \mathrm{m})$. swi6 4 cells harboring an empty vector, however, were significantly larger 

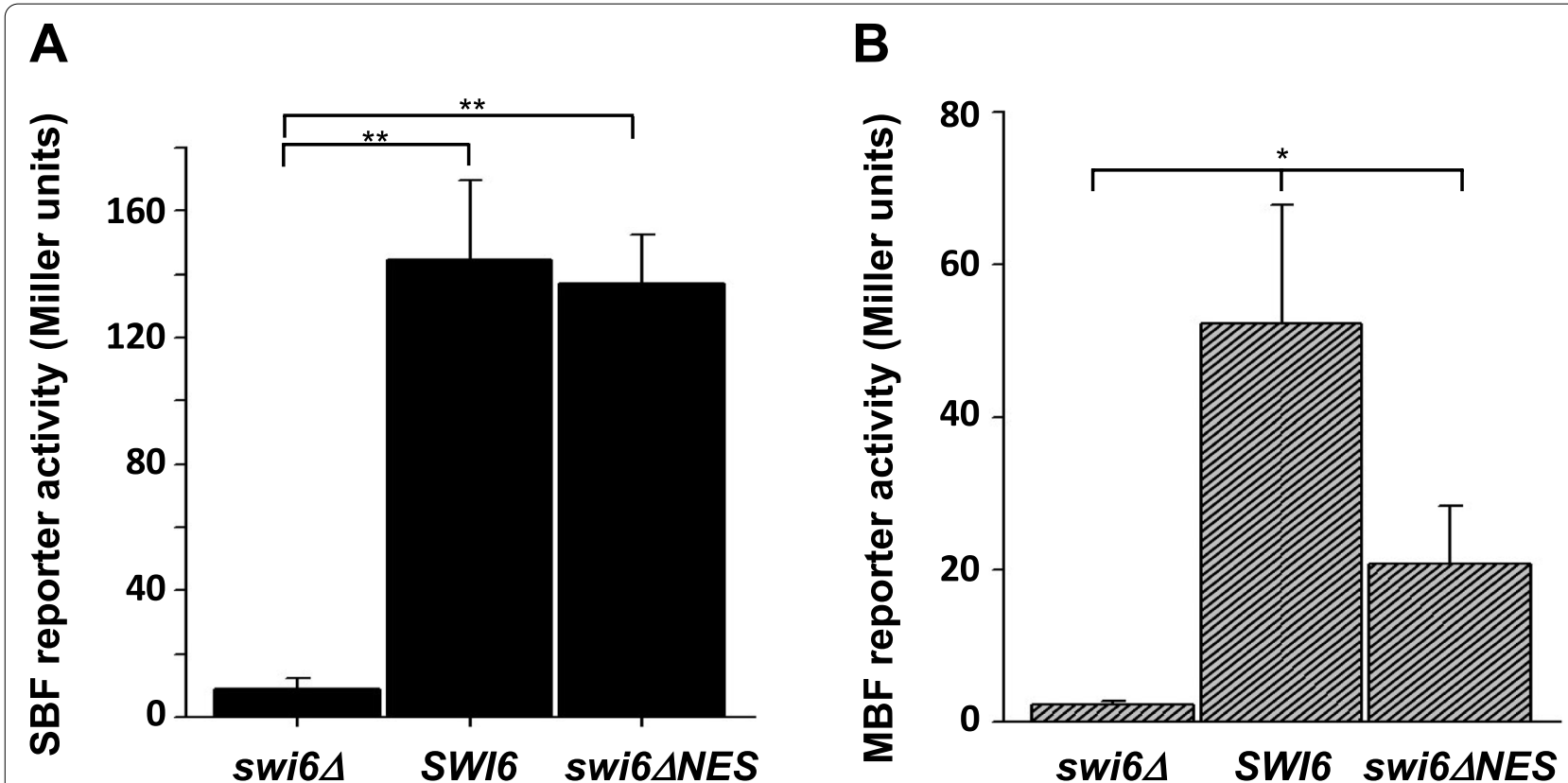

Fig. 4 Alteration of the leucine-rich NES in Swi6 reduces MBF-mediated expression, but not SBF-mediated expression. Yeast containing a swi6 $\triangle$ deletion were transformed with empty vector (swi6A), a centromeric plasmid expressing wild-type SWI6 (SWI6), or a centromeric plasmid expressing full-length SWI6 with each of the leucines in the leucine-rich NES converted to an alanine (swi6 $\triangle N E S$ ). Each strain was also transformed with a reporter plasmid containing either an SBF-response element (A) or MBF-response element (B) upstream of the LacZ gene. Cells were grown to log phase, lysed, and extracts analyzed for $\beta$-galactosidase activity. Bars represent average of at least three assays for each strain. Error bars show s.e.m. for each. ${ }^{* *}=$ significant difference between indicated paired samples using Student's t-test $(p<0.005)$. ${ }^{*}=$ significant difference among the three samples using ANOVA $(p<0.01)$

$(11.82 \mu \mathrm{m} ; \mathrm{SE}=0.68 \mu \mathrm{m} ; p<0.00001)$. Cells expressing swi6 $\triangle N E S$ as their only source of Swi6 protein displayed an intermediate average diameter $(8.47 \mu \mathrm{m} ; \mathrm{SE}=0.08 \mu \mathrm{m})$ that is significantly larger than wild-type cells (average $1.44 \mu \mathrm{m}$ larger; $p<0.01$ ), but is significantly smaller than cells lacking SWI6 (average $3.35 \mu \mathrm{m}$ smaller; $p<0.00005$ ). Thus, the loss of a Crm1-NES in Swi6 (swi6 $\triangle N E S$ ) results in increased cell size but not to the extent observed in a swi64 mutant.

One explanation for the partial cell size phenotype observed in the swi6 $N E S$ mutant is that some Swi6 $\triangle$ NES protein may be exported by Msn5/Kap142, which functions as an exportin for Swi6 [45]. Thus, we investigated whether a deletion of MSN5 exacerbated the swi6 $\triangle N E S$ cell size phenotype. To this end, we generated $m s n 5 \Delta$ yeast expressing swi6 $\triangle N E S$ in the absence of endogenous SWI6. Notably, while a swi6 $m s n 5 \Delta$ double mutant is synthetically lethal [45], such a double mutant expressing swi6 $\triangle N E S$ is viable, indicating that Swi6 lacking this NES sequence is competent to perform its essential activity. With respect to average cell diameter (Fig. 5B), a swi6 $\Delta$ strain $(11.35 \mu \mathrm{m}$; $\mathrm{SE}=1.08 \mu \mathrm{m})$ is significantly larger than any other strain examined (Tukey multiple comparison of means; $p<0.0002)$, confirming previous observations that a complete loss of Swi6 function increases cell size [7]. Interestingly, a swi6ム $m s n 5 \Delta$ strain expressing swi6 $\triangle N E S$ as its sole source of Swi6 is significantly larger $(9.13 \mu \mathrm{m}$; $\mathrm{SE}=0.18 \mu \mathrm{m})$ than either the $m s n 5 \Delta(7.76 \mu \mathrm{m}$; $\mathrm{SE}=0.034 \mu \mathrm{m} ; \mathrm{p}<0.0002)$ or swi6 $\triangle N E S(7.69 \mu \mathrm{m} ; \mathrm{SE}=0.092 \mu \mathrm{m} ; p<0.006)$ mutant alone. That cells with deletions of both the SWI6 NES and MSN5 are significantly larger than wild type cells or either single mutant suggests that Msn5 is involved in mediating some Swi6 function independently of the Swi6 leucine-rich NES. In addition, msn5 swi6 $\mathrm{NES}$ double mutant cells are still significantly smaller than swi6 null cells $(\mathrm{p}<0.0002)$, indicating that Swi6 retains some activity that affects cell size in the absence of Msn5 or Crm1 export.

\section{Discussion}

In this study, we analyzed the nuclear export of the Swi6 transcription factor in yeast and characterized how alterations in export affect phenotypes associated with Swi6 function. We observe that Swi6 shuttles between the nucleus and cytoplasm and that the exportin Crm1 bind to a leucine-rich NES-like sequence in Swi6 with similarity to canonical Crm1 NESs. Removal of the NES-like sequence from Swi6 alters the cell cycle dependent relocalization of Swi6 from the nucleus to 

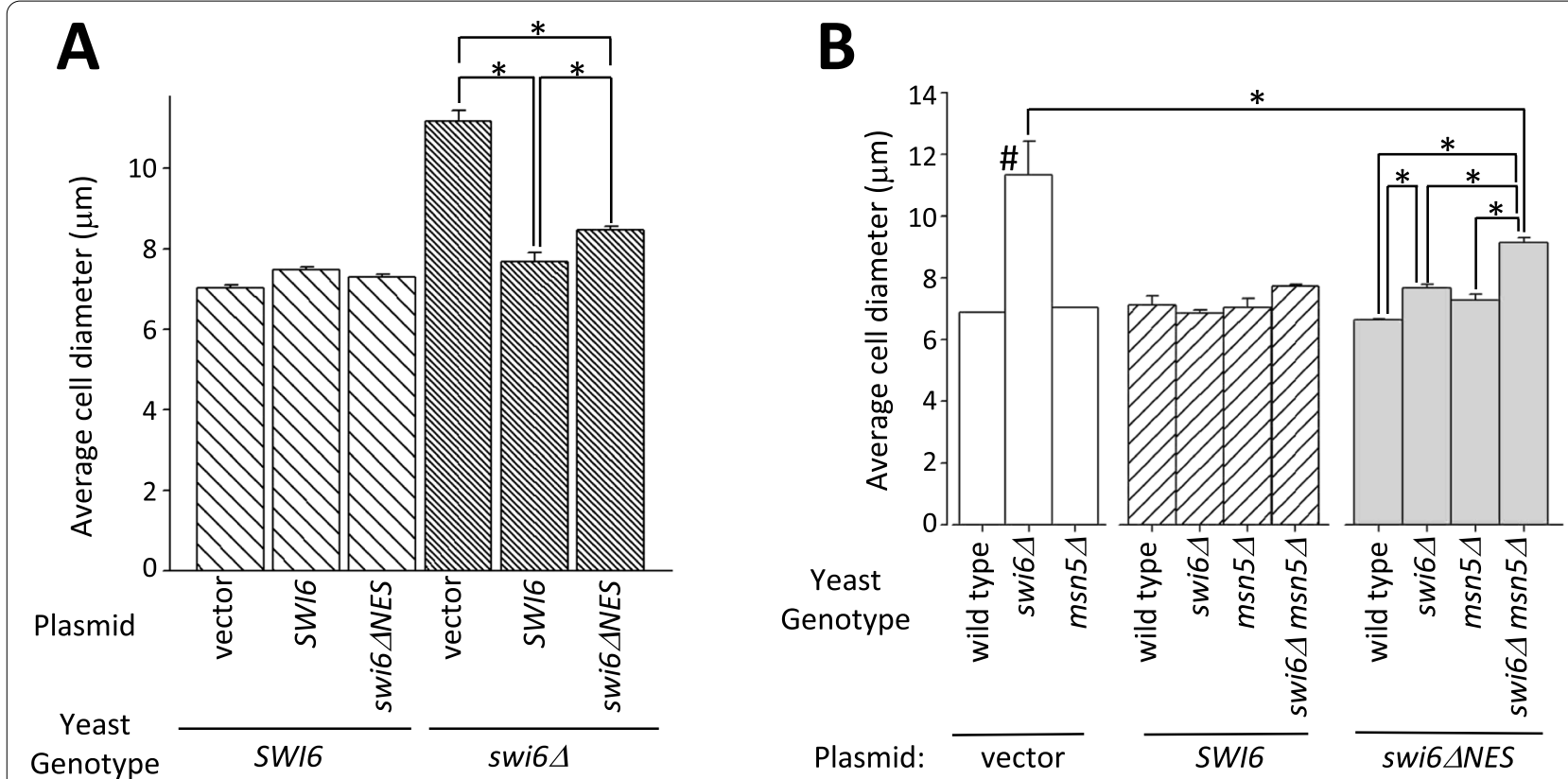

Fig. 5 Swi6 nuclear export mutations result in increased cell size. (A) Cells lacking the Swi6 leucine-rich NES are larger than wild-type cells, but smaller than those completely lacking SWI6. Yeast cells containing genomic wild-type SWI6 (SWI6; wide hashed bars) or a genomic deletion of SWI6 (swi64; narrow hashed bars) were transformed with empty plasmid (vector), plasmid expressing wild-type SWI6 (SWI6), or plasmid containing SWI6 with a mutation that changes $L->A$ at amino acids 250, 254, 257, and 258 (swi6 $\triangle N E S$ ). Bars represent the average cell diameter in $\mu$ m. Error bars represent s.e.m. Asterisks indicate significant differences $\left({ }^{*} p<0.01\right)$. (B) Cells lacking both MSN5 and the Swi6 NES are larger than either single mutant. Wild-type, swi $6 \Delta, m s n 5 \Delta$, and swi $6 \Delta$ msn5 $\Delta$ cells lacking a Swi6 plasmid (gray; swi $6 \Delta$ msn5 $\Delta$ not reported due to synthetic lethality), or containing a plasmid expressing SWI6 (diagonally hashed) or swi6 $\triangle N E S$ (blue) were measured to determine average cell diameter. Bar heights represent average cell diameter in each sample. Error bars indicate s.e.m. for each. Asterisks indicate significant differences between two samples $(p<0.01)$. \# indicates significant difference of sample from all others as examined using the Tukey multiple comparison of means $(p<0.0002)$

cytoplasm, as does inhibition of Crm1 function using leptomycin B. Deletion of the putative Swi6 NES results in a reduction of MBF reporter activity, but not SBF activity, and results in cells that are significantly larger than wild type but not as large as those with a complete swi6 $\Delta$ deletion. Taken together with the work of Queralt and Igual [45], our studies suggest that Swi6 has at least two exportins, Msn5 and Crm1, that each associates with a distinct NES sequence, and that nuclear export by each impacts different aspects of Swi6 function.

Swi6 functions as a transcription factor and requires both nuclear import and export for its activity [40, 43, 45, 50]. Here we provide evidence that individual Swi6 polypeptides are re-imported into the nucleus after export, suggesting that nucleocytoplasmic shuttling is a component of Swi6 function. Our heterokaryon-based shuttling data does not discern whether the nuclear export that occurs during this shuttling process is simply the result of passive diffusion from the nucleus or is actively mediated by exportin proteins. However, at $90 \mathrm{kDa}$, Swi6 is above the $40-60 \mathrm{kDa}$ size threshold of the selectivity barrier for rapid, passive diffusion through NPCs [59-61]. Thus, both the rapid rate at which nuclear accumulation in the second nucleus occurs and the additional evidence for a role for exportins in Swi6 function ([45], this study) suggest that nuclear export of Swi6 is active, regulated, and an important process for its activity.

The work of Queralt and Igual [45] linked the exportin Msn5 to Swi6 function. We have provided evidence that a second exportin, Crm1, is also important not only for Swi6 nuclear export, but also for its activity. Our data indicate that Swi6 and Crm1 interact in vivo and that this interaction takes place via a leucine-rich region within Swi6 with considerable similarity to canonical NESs recognized by Crm1. This observation is supported by high-throughput affinity data identifying Swi6 as being among those proteins interacting with $\mathrm{Crm} 1$ in a RanGTP-dependent manner [28]. Many nucleocytoplasmic transport cargoes associate with more than one karyopherin, including with different exportins functioning to translocate cargoes in the same direction across the NPC $[28,29]$. How might having more than one exportin mediating nuclear export be beneficial to a shuttling protein? The ability of a protein to be exported by multiple exportins may increase the steady-state rate of nuclear 
export, or may enhance the ability to conditionally regulate transport, either by regulating which exportin is present or which NES sequences are available to be bound to facilitate transport. Alternatively, one or more exportins could be functioning largely to remove non-nuclear proteins from the nucleus to prevent aberrant nuclear function, as proposed for Crm1 [28]. In the case of Swi6, it appears that two different exportins, Msn5 and Crm1, associate with distinct NES sequences within the protein ([28, 45], this study) but the function of these distinct interactions is unclear.

Swi6 is transported into the nucleus by more than one karyopherin, being imported both by importin $\alpha-\beta$ (Kap60/Srp1-Kap95) and by Kap120, each of which recognizes a distinct NLS sequence $[40,43,50]$ and each of which appears to mediate nuclear import in response to a different stimulus [40,43,44]. Similarly, the import of STAT proteins in multicellular eukaryotes occurs via two different importins, each of which associates with a distinct NLS [38]. It is noteworthy that the type of karyopherin responsible for import determines which genes the STAT transcription factor will activate [38], suggesting that importins can function in the regulation of interaction with downstream targets after translocation across the NPC.

Here we provide evidence that the nuclear export mediated by $\mathrm{Crm} 1$ and Msn 5 may have distinct roles in Swi6 function. While a yeast mutant lacking Msn5 has a significantly reduced level of SBF-mediated, but not MBF-mediated, reporter gene expression [45], yeast expressing Swi6 lacking the putative Crm1 NES as their only source of Swi6 exhibit significantly reduced expression of an MBF reporter, but no reduction of an SBF reporter (Fig. 4). It is interesting that a loss of a functional NES resulting in nuclear retention of a transcription factor could result in decreased expression of a gene activated by that transcription factor. However, the export of Swi6 by Msn 5 is required to activate Swi6 SBF activity [45], providing a model for Crm1 function in Swi6 MBF activation. Our data suggest that Crm1-mediated export of Swi6 may be important for the transcription activation function of MBF, but not of SBF, providing evidence that Crm1 and Msn5 are each important for a different aspect of Swi6 function. Alternatively, this mutation could alter the ability of Swi6 to associate with Mbp1. Analysis of changes in expression levels of endogenous Swi6 targets in cells with an altered Swi6 putative NES and investigation of Mbp1 interactions with Swi6 mutants will allow further characterization of the effects of Swi6 shuttling on regulated gene expression.

The observed changes in cell size provide further evidence that both Msn 5 and Crm1 are important, but not essential, for Swi6 function. A deletion of SWI6 results in a nearly $50 \%$ increase in average cell diameter in yeast $([7,45]$; Fig. 5A, B). We observe here that reducing Crm1-mediated Swi6 export through mutagenesis of the leucine-rich NES-like region of Swi6 also results in a significant increase in cell size over wild-type, but not nearly the increase observed in swi6 $\Delta$ cells. While cells deleted for MSN5 may trend toward being slightly larger than wild type, we do not observe a statistically significant difference. However, the combination of a swi6 $\triangle N E S$ mutation and $m s n 5 \Delta$ deletion results in cells larger than either single mutant alone (Fig. 5B). This synthetic phenotype upon reduction of both Msn5- and Crm1-mediated export of Swi6 provides further evidence that both exportins have some role in cell size regulation in yeast and, at least in the case of Crm1, that Swi6 is involved in mediating this role. The differences in size observed for

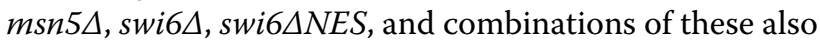
provide further evidence that Msn5 and Crm1 provide distinct roles in mediating Swi6 function.

Interestingly, msn5 5 swi $6 \triangle N E S$ cells are viable, unlike $m s n 5 \Delta$ swi $6 \Delta$ cells, and have an average diameter smaller than swi6 6 alone, indicating that Swi6 retains some function, even when both Msn5 and Crm1 transport are reduced. There are several possible explanations for this retention of Swi6 function in the msn5 5 swi6 $2 N E S$ double mutant. One possibility is that nuclear export may not be necessary for all functions of Swi6, even though Msn5and Crm1-mediated export are each important for some independent transcriptional activities ([45]; Fig. 4). Alternatively, there may be some residual Swi6 export occurring in the $m s n 5 \Delta$ swi $6 \triangle N E S$ double mutant, either via Crm1, some other exportin, or passive diffusion through the NPC. Our data indicate that removing the putative Crm1-NES does not eliminate Swi6 export completely (Fig. 3C), suggesting that either $\mathrm{Crm} 1$ or some other exportin remains able to transport Swi6 $\triangle$ NES efficiently enough to retain the activity necessary for viability in the absence of Msn5. An interesting question is whether or not there is something functionally distinct about the Swi6 protein exported by Msn 5 and that exported by $\mathrm{Crm} 1$, and whether this difference is mediated via a physical alteration, either through a post-translational modification, dimerization (or multimerization) with another polypeptide, or some other form of chemical or physical regulation of Swi6. The nuclear import of Swi6 is highly regulated, with post-translational modifications in response to specific stimuli determining which karyopherin mediates import and which genes are transcriptionally activated, leaving open the question of whether Swi6 export is similarly regulated by phosphorylation, multimerization, or other post-translational influences. It also remains possible that Swi6 export is not required for all Swi6 activity and that some transcription activation 
or other activity that impacts cell size remains functional even in the absence of Msn5 and Crm1-mediated Swi6 export.

The intracellular localization of Swi6 is important for regulating its activity as a transcription factor and our data use Swi6 as a model protein to provide strong evidence that transcription factor regulation by translocation across the nuclear envelope is considerably more complex than simple compartmentalization of the activating protein in the nucleus or cytoplasm. These data provide a foundation for further investigation of the relationship between nucleocytoplasmic transport and the role of targeting motifs within protein in influencing protein modification and activity. This study also brings the number of karyopherins identified as being involved in regulating Swi6 function to four (Kap- $\alpha / \beta$ and Kap120 importins; Msn5 and Crm1 exportins) and highlights the importance of regulated nucleocytoplasmic transport on transcription factor function. The data reported here provide evidence that Msn 5 and Crm 1 are both important for Swi6 function and, interestingly, that each is important for activating different Swi6 targets. Future studies should provide insight into the complex interplay between nuclear import/export mechanisms, how the interaction between transport substrates and each of their importins and exportins is initiated and regulated, and how this interaction ultimately affects the activity of proteins that undergo nucleocytoplasmic shuttling, including Swi6 and other transcription factors.

\section{Conclusions}

Swi6 undergoes nucleocytoplasmic shuttling, with nuclear export mediated by at least two different exportins, Crm1/Xpo1 and Msn5. We identify a putative nuclear export signal for Crm1 within Swi6 that is necessary for efficient nuclear export in a cell cycledependent pattern. We also observe that a loss of Swi6 export by Crm1 reduces MBF-mediated, but not SBFmediated gene expression. This study brings the number of karyopherins involved in regulating Swi6 function to four (Kap- $\alpha / \beta$ and Kap120 importins; Msn5 and Crm1 exportins) and highlights the importance of regulated nucleocytoplasmic transport on transcription factor function. Taken with the observation by Queralt and Igual (2003) that Msn5-mediated Swi6 export is required for SBF, but not MBF, transcriptional activity, the data reported here provide new insights into the complex regulation of Swi6 transcription activation activity and the role of nucleocytoplasmic shuttling in regulated gene expression.

\section{Materials and methods}

\section{Strains, plasmids, and growth conditions}

Yeast strains used in this study are listed in Table 1. Yeast strains were cultured at $30^{\circ} \mathrm{C}$ unless otherwise stated. Yeast cell culture and media preparation were performed essentially as in Sherman et al. [63]. Yeast transformations were performed as described [64]. Plasmids used in this study are listed in Table 2. E. coli cells were cultured at $37^{\circ} \mathrm{C}$ and plasmid isolation was carried out using a Qiagen Plasmid Mini Kit (Qiagen, Germantown, MD) according to manufacturer instructions. pKBB353 (pSwi6 ${ }^{1-181}$-GFP) was generated by PCR amplification of the SWI6 promoter and first 543 nucleotides of the SWI6 coding region using upstream primer $5^{\prime}$-TACCGGGCC CCCCCTCGAGGTCGACGGTATCGATAAGCTTGA TATCGAATTCTTGCAGGTCACTGTCTTCTGCTT CACTC-3' and downstream primer 5'- CTAATTCAA CAAGAATTGGGACAACTCCAGTGAAGAGTTCTT CTCCTTTGCTATTCGGAGTGGAGTCACTCTCAGC

Table 1 Yeast strains used in this study

\begin{tabular}{|c|c|c|}
\hline Strain name & Genotype & Source \\
\hline BY4741 & MATa his3 leu2 ura3 met15 & OpenBiosystems \\
\hline BY4742 & MATa his3 leu2 ura3 lys2 & OpenBiosystems \\
\hline KBY893 & MATa msn5 $\Delta$ his3 leu2 ura3 met15 & OpenBiosystems \\
\hline KBY1364 & MATa msn5 $\triangle$ his3 leu2 ura3 lys2 & OpenBiosystems \\
\hline KBY1448 & MATa swi6 $\triangle$ his3 leu2 ura3 met 15 & OpenBiosystems \\
\hline KBY1544 & MATa swi6 $\triangle$ his3 leu2 ura3 met15 + pRS315 & This study \\
\hline KBY1546 & MATa swi6 $\triangle$ his3 leu2 ura3 met15 + pAC1571 & This study \\
\hline KBY1548 & MATa swi6 $\Delta$ his3 leu2 ura3 met15 + pKBB441 & This study \\
\hline MS739 & MATa kar1-1 ade2 ura3 leu2 & [48] \\
\hline PJ69-4a & $\begin{array}{l}\text { MATa trp1-901 leu2-3112 ura3-52 his3-200 } \\
\text { gal4 gal80 LYS2::GAL1-HIS3 GAL2-ADE2 met2::GAL7-lacZ }\end{array}$ & {$[62]$} \\
\hline PJ69-4a & $\begin{array}{l}\text { MATa trp1-901 leu2-3112 ura3-52 his3-200 } \\
\text { gal4 gal80 LYS2::GAL1-HIS3 GAL2-ADE2 met2::GAL7-lacZ }\end{array}$ & {$[62]$} \\
\hline
\end{tabular}


Table 2 Plasmids used in this study

\begin{tabular}{|c|c|c|}
\hline Plasmid number & Genotype & Source \\
\hline pRS315 & CENLEU2 & {$[65]$} \\
\hline pKBB353 & CEN URA3 SWI6 $6^{1-181}$-GFP & This study \\
\hline pKBB354 & CEN URA3 SWI6 $6^{1-273}$-GFP & This study \\
\hline pKBB416 & CEN URA3 SWI $6^{1-273} \triangle N E S-G F P$ & This study \\
\hline pKBB484 & CEN URA3 GAL1::SWI6-GFP & This study \\
\hline pGAL::CCA1-GFP & CEN URA3 GAL1::CCA1-GFP & {$[46]$} \\
\hline $\mathrm{pGAL}:: \mathrm{H} 2 \mathrm{~B}-\mathrm{GFP}$ & CEN URA3 GAL1::H2B-GFP & {$[46]$} \\
\hline pAC1202 & CEN TRP1 SWI6-GFP & {$[43]$} \\
\hline pAC1571 & CEN LEU2 SWI6-GFP & {$[43]$} \\
\hline pKBB418 & 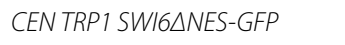 & This study \\
\hline pKBB441 & CEN LEU2 SWI6 $\triangle N E S-G F P$ & This study \\
\hline pOBD-2 & CENTRP1 GAL4-BD & {$[56]$} \\
\hline $\mathrm{pOAD}$ & CEN LEU2 GAL4-AD & {$[56]$} \\
\hline pKBB486 & CEN TRP1 CRM1-BD & This study \\
\hline pKBB491 & CEN LEU2 SWI6-AD & This study \\
\hline pBA251 & CEN URA3 4 X SCB::LaCZ & {$[4]$} \\
\hline pBA487 & CEN URA3 4 X MCB::LaCZ & {$[4]$} \\
\hline pLDB235 & CEN URA3 GAL1 & L. Davis \\
\hline pLDB350 & CEN URA3 GFP & {$[66]$} \\
\hline
\end{tabular}

$-3^{\prime}$, followed by homologous recombination into SpeI digested pLDB350. pKBB354 (Swi6 ${ }^{1-273}$-GFP) was generated in the same way using PCR primers 5 ' - TACCGG GCCCCCCCTCGAGGTCGACGGTATCGATAAGCT TGATATCGAATTCTTGCAGGTCACTGTCTTCTG CTTCACTC $-3^{\prime}$ and 5'-CTAATTCAACAAGAATTG GGACAACTCCAGTGAAGAGTTCTTCTCCTTTGC TGCTGTCATTATTAAGGGATGTAGGC- $3^{\prime}$ to amplify the promoter and first 819 nucleotides of SWI6. Plasmids pKBB354, pAC1202, and pAC1571 all were mutagenized to change codons encoding leucines to those for alanines at residues 250, 254, 257, and 258 using Quik-Change Site Directed Mutagenesis (Agilent Technologies, Santa Clara, CA) and primer 5'-GTTGTAAATGATAATGAA CAGAAGATGAAAGCAGAGGCATTCGCACAACGG GCGGCATTTCCAGAAATTCAAGAAATGCCTACA TCCC-3', resulting in Swi6 $\triangle N E S$ plasmids pKBB416, pKBB418, and pKBB441, respectively. Full-length SWI6 was cloned into pLDB235 behind the GAL1 promoter by PCR amplification of SWI6 from genomic DNA using oligonucleotides 5'-ATTGTTAATATACCTCTATACTTT AACGTCAAGGAGAAAAAACTATAATGGCGTTGG

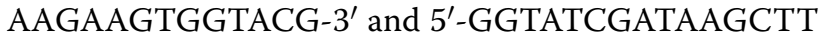
GATATCGAATTCCTGCAGCCCGGGGGATCCACT AGTTCTTTAGCAGCCGGATCCTTTG-3', followed by homologous recombination to make pKBB484. Two hybrid plasmid pKBB486 (Crm1-BD) was constructed by PCR amplification of full-length CRM1 using oligonucleotides 5 '-TGAAGATACCCCACCAAACCCAAA
AAAAGAGATCGAATTCCAGCTGACCACCATGGA AGGAATTTTGGATTTTTCTAACG- $3^{\prime}$ and $5^{\prime}$-TTT TCAGTATCTACGATTCATAGATCTCTGCAGGTC GACGGATCCCCGGGAATTGCCATGTAATCATCA AGTTCGGAAGG-3', transformation into yeast with linearized pOBD-2, and homologous recombination. Plasmid pKBB491 (Swi6-AD) was generated in the same way using $\mathrm{POAD}$ and the $\mathrm{PCR}$ product resulting from amplification of SWI6 using primers 5'-GATGATGAAGATACC CCACCAAACCCAAAAAAAGAGATCGAATTCCAG CTGACCACCATGGCGTTGGAAGAAGTGGTACG-3' and 5'-GGGTTTTTCAGTATCTACGATTCATAGATC TCTGCAGGTCGACGGATCCCCGGGAATTGCCAT GCCCTCATGAAGCATGC-3'. All plasmids were subjected to DNA sequencing to confirm correct nucleotide sequence in all inserts.

\section{Fluorescence microscopy}

Fluorescence microscopy was used to visualize live cells containing each Swi6-GFP fusion. Cells were grown overnight at $30^{\circ} \mathrm{C}$ or $25^{\circ} \mathrm{C}$ in SD-Ura media. Two hours prior to microscopy, cells were diluted 20-fold. Cells were also examined after synchronization by $\alpha$-factor treatment as described [67]. To release cells from arrest, $\alpha$-factor was rinsed away twice with SD -Ura media, cells were incubated in selective media, and observation of nuclear versus cytoplasmic Swi6-GFP localization was recorded from more than 100 cells per timepoint. Nuclear fluorescence was defined as having fluorescence of greater intensity within the nucleus and a clearly defined transition between nucleus and cytoplasm. All cells without clearly defined nuclear fluorescence were scored as "cytoplasmic." All assays were done in triplicate or greater. Photomicrographs were taken using Nikon E400 microscopes with SPOT $\mathrm{RT}_{\mathrm{KE}}$ cameras and SPOT Advanced software (Diagnostic Instruments, Sterling Heights, MI).

\section{Heterokaryon assay}

BY4741 wild type yeast containing either pKBB484 (GAL1::SWI6-GFP), pGAL::CCA1-GFP, or pGAL::H2BGFP $[46,49]$ were grown overnight in SD -Ura media, then rinsed and resuspended in selective media with $2 \%$ raffinose for $3 \mathrm{~h}$ at $30^{\circ} \mathrm{C}$. After culture in raffinose, cells were washed twice with selective media containing $2 \%$ galactose and incubated $2 \mathrm{~h}$ at $30^{\circ} \mathrm{C}$ in SD -Ura with $2 \%$ galactose. Cells were then washed twice with SD-Ura with $2 \%$ glucose and incubated $2 \mathrm{~h}$ at $30^{\circ} \mathrm{C}$. Heterokaryon formation and shuttling assays were performed essentially as described in Feng and Hopper [46]. Briefly, karyogamy mutant strain MS739 (kar1-1) and BY4741 cells containing pKBB484, pGAL::Cca1-GFP, or pGAL::H2BGFP were vacuum filtered together onto a nitrocellulose filter and incubated on solid YPD media for $2 \mathrm{~h}$ to allow 
zygote formation. Cells were then scraped off of the filter, fixed in $70 \%$ ethanol, and DAPI stained for analysis by direct fluorescence microscopy and photomicroscopy as described above.

\section{Two-hybrid analysis}

The yeast two hybrid system [55] was used to test for protein-protein interactions. Yeast strains PJ69-4a and PJ69-4 $\alpha$ were respectively transformed with plasmids pOAD and pOBD-2; KBB491 (Swi6 ${ }^{\mathrm{AD}}$ ) and pOBD-2; $\mathrm{KBB} 491\left(\mathrm{Swi}^{\mathrm{AD}}\right)$ and $\mathrm{KBB} 486\left(\mathrm{Crm1}^{\mathrm{BD}}\right)$; and pOAD \& KBB486 $\left(\mathrm{Crm}^{\mathrm{BD}}\right)$. The haploid transformants were mated and the resulting diploids were plated in 10-fold serial dilutions onto SD -Leu-Trp and SD -Leu-Trp-Ade plates and grown at $30^{\circ} \mathrm{C}$. Cells were visually assayed for growth and photographed after 48 and $72 \mathrm{~h}$. Strains containing the same plasmid combinations were also assayed for $\beta$-galactosidase activity by cell lysis and colorimetric CPRG assay as described [52]. Miller units of $\beta$-galactosidase activity were calculated using the method of [68]. Statistical comparison of overall variation was performed by analysis of variance. Comparisons between conditions were performed by Tukey multiple comparisons of means at a $95 \%$ family-wise confidence level.

\section{SBF- and MBF-activity assays}

Cells were assayed for SBF or MBF activity using the pBA251 (4X SCB::LacZ) and pBA482 (4X MCB::LacZ) plasmids [4]. Briefly, yeast strains deleted for SWI6 (swi64) were co-transformed with either SWI6 (pAC1571), swi6 $N E S$ (pKBB441), or empty vector (pRS315) plasmids in combination with pBA251 or pBA482. Transformants were isolated on SD -Leu Ura selective media, cultured in liquid media, lysed, and assayed for $\beta$-galactosidase activity. Miller units of $\beta$-galactosidase activity were calculated as per [68]. Statistical comparisons between strains within each group were performed using Tukey multiple comparisons of means at a $95 \%$ confidence level.

\section{Cell size analysis}

To generate viable swi6 $m s n 5 \Delta$ strains containing swi6 mutations, we mated isogenic BY4741 and BY4742 yeast lacking SWI6 and MSN5, respectively, and transformed the resulting diploid cells with empty vector or a plasmid expressing SWI6 or swi6 $N E S$. We then sporulated the transformed diploid cells and performed tetrad dissections on selective media to generate wild type, swi $6 \Delta$, $m s n 5 \Delta$, and swi $6 \Delta m s n 5 \Delta$ cells containing each plasmid. Yeast strains were grown to $A_{600}=0.2-0.6$ in $10 \mathrm{ml}$ of selective media at $25^{\circ} \mathrm{C}$, and $50 \mu \mathrm{l}$ samples were diluted in $150 \mathrm{ml} 1 \mathrm{M} \mathrm{NaCl}$ and vortexed. Cell size was measured using an Elzone II Particle Size Analyzer (Micromeritics, Norcross, GA) as per manufacturer's instructions. Three independent cultures of each yeast strain were measured and all cultures were analyzed in triplicate. Pairwise comparison of every combination of strains was made by Tukey multiple comparison of means at a $95 \%$ familywise confidence level. Raw particle size data was analyzed using Microsoft Excel and SigmaPlot software.

\begin{abstract}
Acknowledgements
The authors wish to thank Anita Corbett, Anita Hopper, Laura Davis, Brenda Andrews, and members of Stan Fields'lab for sharing of plasmids, strains, and reagents. We thank Kate Kokanovich and Amy Sullivan for technical contributions, Tim McCay and Larry Schweitzer for guidance and assistance with statistical analyses, undergraduate members of the Belanger lab for intellectual contributions and insightful discussions, Steve Haase for helpful suggestions, and Bob Skibbens for critically reading the manuscript.
\end{abstract}

\section{Authors' contributions}

KDB designed and managed the project; KDB, WTY, MFB, ANR, MAP, EKD, NH, SJG, and KGB performed the experiments and analyzed the data; KDB, WTY, $M F B$, EKD, and KH prepared the figures; KDB wrote the manuscript; WTY, MFB, ANR, MAP, EKD, NH, SJG, and KGB reviewed and edited the manuscript. All authors read and approved the final manuscript.

\section{Funding}

This work was supported by National Institutes of Health grant R15-GM065107 to KDB and by Colgate University through the Faculty Research Council, the Stuart Updike Endowed Undergraduate Research Fund, and generous funding in support of summer and academic year undergraduate research.

\section{Availability of data and materials}

The data used and analyzed during the reported study are available from the corresponding author upon request. DNA sequences for Swi6 truncations and NES mutants are available via GenBank accession numbers OK173596 $\left(\right.$ Swi $\left.^{1-181}\right)$, OK173597 (Swi6 $\left.{ }^{1-273}\right)$, OK173598 (Swi6 $\left.{ }^{1-273} \Delta N E S\right)$, and OK173599 (Swi6 $\triangle N E S)$

\section{Declarations}

Ethics approval and consent to participate

Not applicable. No animals or human subjects were used in this study.

\section{Consent for publication}

Not applicable.

\section{Competing interests}

The authors declare no competing interests.

\section{Author details}

${ }^{1}$ Department of Biology, Colgate University, Hamilton, NY, USA. ${ }^{2}$ Present Address: Immunology Program, Memorial Sloan Kettering Cancer Center, New York, NY, USA. ${ }^{3}$ Present Address: Department of Biology, University of Oregon, Eugene, OR, USA. ${ }^{4}$ Present Address: The Estée Lauder Companies, Inc., Mellville, NY, USA. ${ }^{5}$ Present Address: Department of Emergency Medicine, Rochester General Hospital, Rochester, NY, USA. ${ }^{6}$ Present Address: Department of Emergency Medicine, Cooper University Health Care, Camden, NJ, USA. ${ }^{7}$ Present Address: Kerry's Place Autism Services, Aurora, ON, Canada. ${ }^{8}$ Present Address: Department of Chemistry, Colgate University, Hamilton, NY, USA. ${ }^{9}$ Present Address: Center for Learning, Teaching, and Research, Colgate University, Hamilton, NY, USA.

Received: 7 September 2021 Accepted: 7 February 2022 Published online: 21 February 2022 


\section{References}

1. Fisher RP. Getting to S: CDK functions and targets on the path to cellcycle commitment. F1000Res. 2016;5. https://doi.org/10.12688/f1000 research.9463.1.

2. Johnson A, Skotheim JM. Start and the restriction point. Curr Opin Cell Biol. 2013;25:717-23.

3. Cho RJ, Campbell MJ, Winzeler EA, Steinmetz L, Conway A, Wodicka L, et al. A genome-wide transcriptional analysis of the mitotic cell cycle. Mol Cell. 1998:2:65-73.

4. Costanzo M, Schub O, Andrews B. G1 transcription factors are differentially regulated in Saccharomyces cerevisiae by the Swi6-binding protein Stb1. Mol Cell Biol. 2003:23:5064-77.

5. Ferrezuelo F, Colomina N, Futcher B, Aldea M. The transcriptional network activated by $\mathrm{Cln} 3$ cyclin at the G1-to-S transition of the yeast cell cycle. Genome Biol. 2010;11:R67.

6. Spellman PT, Sherlock G, Zhang MQ, lyer VR, Anders K, Eisen MB, et al. Comprehensive identification of cell cycle-regulated genes of the yeast Saccharomyces cerevisiae by microarray hybridization. Mol Biol Cell. 1998;9:3273-97.

7. Wijnen $\mathrm{H}$, Landman A, Futcher B. The $\mathrm{G}(1)$ cyclin Cln3 promotes cell cycle entry via the transcription factor Swi6. Mol Cell Biol. 2002;22:4402-18.

8. Futcher B. Transcriptional regulatory networks and the yeast cell cycle. Curr Opin Cell Biol. 2002;14:676-83.

9. Jorgensen P, Tyers M. How cells coordinate growth and division. Curr Biol. 2004:14:R1014-27.

10. Stillman DJ. Dancing the cell cycle two-step: regulation of yeast G1-cellcycle genes by chromatin structure. Trends Biochem Sci. 2013:38:467-75.

11. Flick K, Wittenberg C. Multiple pathways for suppression of mutants affecting G1-specific transcription in Saccharomyces cerevisiae. Genetics. 2005;169:37-49.

12. Dončić A, Falleur-Fettig M, Skotheim JM. Distinct interactions select and maintain a specific cell fate. Mol Cell. 2011;43:528-39. https://doi.org/10. 1016/j.molcel.2011.06.025

13. Eser U, Falleur-Fettig M, Johnson A, Skotheim JM. Commitment to a cellular transition precedes genome-wide transcriptional change. Mol Cell. 2011:43:515-27. https://doi.org/10.1016/j.molcel.2011.06.024.

14. Bean JM, Siggia ED, Cross FR. High functional overlap between Mlul cell-cycle box binding factor and Swi $4 / 6$ cell-cycle box binding factor in the G1/S transcriptional program in Saccharomyces cerevisiae. Genetics. 2005;171:49-61.

15. Breeden L, Nasmyth K. Cell cycle control of the yeast $\mathrm{HO}$ gene: cis- and trans-acting regulators. Cell. 1987:48:389-97.

16. Koch C, Moll T, Neuberg M, Ahorn H, Nasmyth K. A role for the transcription factors Mbp1 and Swi4 in progression from G1 to S phase. Science. 1993:261:1551-7.

17. Hendler A, Medina EM, Buchler NE, de Bruin RAM, Aharoni A. The evolution of a G1/S transcriptional network in yeasts. Curr Genet. 2018:64:81-6. https://doi.org/10.1007/s00294-017-0726-3.

18. Andrews BJ, Moore LA. Interaction of the yeast Swi4 and Swi6 cell cycle regulatory proteins in vitro. Proc Natl Acad Sci USA. 1992;89:11852-6.

19. Lowndes $N F$, Johnson $A L$, Breeden $L$, Johnston LH. SWI6 protein is required for transcription of the periodically expressed DNA synthesis genes in budding yeast. Nature. 1992;357:505-8.

20. de Bruin RAM, Kalashnikova TI, Chahwan C, McDonald WH, Wohlschlegel J, Yates J, et al. Constraining G1-specific transcription to late G1 phase: the MBF-associated corepressor Nrm1 acts via negative feedback. Mol Cell. 2006:23:483-96.

21. Wittenberg C, Reed SI. Cell cycle-dependent transcription in yeast: promoters, transcription factors, and transcriptomes. Oncogene. 2005:24:2746-55

22. Lange A, Mills RE, Lange CJ, Stewart M, Devine SE, Corbett AH. Classical nuclear localization signals: definition, function, and interaction with importin alpha. J Biol Chem. 2007;282:5101-5.

23. Soniat M, Chook YM. Nuclear localization signals for four distinct karyopherin- $\beta$ nuclear import systems. Biochem J. 2015;468:353-62. https://doi.org/10.1042/BJ20150368.

24. Mosammaparast N, Pemberton LF. Karyopherins: from nucleartransport mediators to nuclear-function regulators. Trends Cell Biol. 2004;14:547-56.

25. Xu D, Farmer A, Chook YM. Recognition of nuclear targeting signals by Karyopherin- $\beta$ proteins. Curr Opin Struct Biol. 2010;20:782-90.
26. Görlich D, Seewald MJ, Ribbeck K. Characterization of Ran-driven cargo transport and the RanGTPase system by kinetic measurements and computer simulation. EMBO J. 2003:22:1088-100.

27. Lee SJ, Matsuura Y, Liu SM, Stewart M. Structural basis for nuclear import complex dissociation by RanGTP. Nature. 2005:435:693-6.

28. Kırlı K, Karaca S, Dehne HJ, Samwer M, Pan KT, Lenz C, et al. A deep proteomics perspective on CRM1-mediated nuclear export and nucleocytoplasmic partitioning. Elife. 2015;4.

29. Mackmull M, Klaus B, Heinze I, Chokkalingam M, Beyer A, Russell RB, et al. Landscape of nuclear transport receptor cargo specificity. Mol Syst Biol. 2017;13. https://doi.org/10.15252/msb.20177608.

30. Thakar K, Karaca S, Port SA, Urlaub H, Kehlenbach RH. Identification of CRM1-dependent Nuclear Export Cargos Using Quantitative Mass Spectrometry. Mol Cell Proteomics. 2013;12:664-78.

31. Fornerod M, Ohno M, Yoshida M, Mattaj IW. CRM1 is an export receptor for leucine-rich nuclear export signals. Cell. 1997:90:1051-60.

32. Kutay U, Güttinger S. Leucine-rich nuclear-export signals: born to be weak. Trends Cell Biol. 2005:15:121-4.

33. Quan Y, Ji Z-L, Wang X, Tartakoff AM, Tao T. Evolutionary and transcriptional analysis of karyopherin beta superfamily proteins. Mol Cell Proteomics. 2008;7:1254-69.

34. Ghosh S, Karin M. Missing pieces in the NF-kappaB puzzle. Cell. 2002;109(Suppl):S81-96.

35. Hayden MS, Ghosh S. Shared principles in NF-kappaB signaling. Cell. 2008:132:344-62

36. Derynck R, Zhang Y, Feng XH. Smads: transcriptional activators of TGFbeta responses. Cell. 1998;95:737-40.

37. Logan CY, Nusse R. The Wnt signaling pathway in development and disease. Annu Rev Cell Dev Biol. 2004:20:781-810.

38. Meyer T, Begitt A, Lödige I, van Rossum M, Vinkemeier U. Constitutive and IFN-gamma-induced nuclear import of STAT1 proceed through independent pathways. EMBO J. 2002;21:344-54

39. Roth J, Dobbelstein M, Freedman DA, Shenk T, Levine AJ. Nucleo-cytoplasmic shuttling of the hdm2 oncoprotein regulates the levels of the p53 protein via a pathway used by the human immunodeficiency virus rev protein. EMBO J. 1998;17:554-64.

40. Kim K-Y, Truman AW, Caesar S, Schlenstedt G, Levin DE. Yeast Mpk1 cell wall integrity mitogen-activated protein kinase regulates nucleocytoplasmic shuttling of the Swi6 transcriptional regulator. Mol Biol Cell. 2010;21:1609-19.

41. Sidorova JM, Mikesell GE, Breeden LL. Cell cycle-regulated phosphorylation of Swi6 controls its nuclear localization. Mol Biol Cell. 1995:6:1641-58.

42. Taba MR, Muroff I, Lydall D, Tebb G, Nasmyth K. Changes in a SWI4,6-DNAbinding complex occur at the time of $\mathrm{HO}$ gene activation in yeast. Genes Dev. 1991;5:2000-13.

43. Harreman MT, Kline TM, Milford HG, Harben MB, Hodel AE, Corbett AH. Regulation of nuclear import by phosphorylation adjacent to nuclear localization signals. J Biol Chem. 2004;279:20613-21.

44. Geymonat M, Spanos A, Wells GP, Smerdon SJ, Sedgwick SG. Clb6/Cdc28 and $\mathrm{Cdc} 14$ regulate phosphorylation status and cellular localization of Swi6. Mol Cell Biol. 2004;24:2277-85.

45. Queralt $E$, Igual JC. Cell cycle activation of the Swi6p transcription factor is linked to nucleocytoplasmic shuttling. Mol Cell Biol. 2003:23:3126-40.

46. Feng W, Hopper AK. A Los 1 p-independent pathway for nuclear export of intronless tRNAs in Saccharomycescerevisiae. Proc Natl Acad Sci USA. 2002:99:5412-7.

47. Conde J, Fink GR. A mutant of Saccharomyces cerevisiae defective for nuclear fusion. Proc Natl Acad Sci USA. 1976:73:3651-5.

48. Vallen EA, Hiller MA, Scherson TY, Rose MD. Separate domains of KAR mediate distinct functions in mitosis and nuclear fusion. J Cell Biol. 1992;117:1277-87.

49. Mosammaparast N, Jackson KR, Guo Y, Brame CJ, Shabanowitz J, Hunt DF, et al. Nuclear import of histone $\mathrm{H} 2 \mathrm{~A}$ and $\mathrm{H} 2 \mathrm{~B}$ is mediated by a network of karyopherins. J Cell Biol. 2001:153:251-62.

50. Taberner FJ, Igual JC. Yeast karyopherin Kap95 is required for cell cycle progression at Start. BMC Cell Biol. 2010;11:47.

51. Stade K, Ford CS, Guthrie C, Weis K. Exportin 1 (Crm1p) is an essential nuclear export factor. Cell. 1997;90:1041-50.

52. Finn EM, DeRoo EP, Clement GW, Rao S, Kruse SE, Kokanovich KM, et al. A subset of FG-nucleoporins is necessary for efficient Msn5-mediated 
nuclear protein export. Biochim Biophys Acta. 2013;1833:1096-103. https://doi.org/10.1016/j.bbamcr.2012.12.020.

53. Shulga N, Roberts P, Gu Z, Spitz L, Tabb MM, Nomura M, et al. In vivo nuclear transport kinetics in Saccharomyces cerevisiae: a role for heat shock protein 70 during targeting and translocation. J Cell Biol. 1996;135:329-39.

54. Strawn LA, Shen T, Shulga N, Goldfarb DS, Wente SR. Minimal nuclear pore complexes define FG repeat domains essential for transport. Nat Cell Biol. 2004;6:197-206.

55. Fields S, Song $\mathrm{O}$. A novel genetic system to detect protein-protein interactions. Nature. 1989;340:245-6.

56. Cagney G, Uetz P, Fields S. High-throughput screening for protein-protein interactions using two-hybrid assay. Meth Enzymol. 2000;328:3-14.

57. Neville M, Rosbash M. The NES-Crm1 pexport pathway is not a major mRNA export route in Saccharomyces cerevisiae. EMBO J. 1999;18:3746-56.

58. Kudo N, Matsumori N, Taoka H, Fujiwara D, Schreiner EP, Wolff B, et al. Leptomycin B inactivates CRM1/exportin 1 by covalent modification at a cysteine residue in the central conserved region. Proc Natl Acad Sci USA. 1999;96:9112-7.

59. Li C, Goryaynov A, Yang W. The selective permeability barrier in the nuclear pore complex. Nucleus. 2016;7:430-46.

60. Mohr D, Frey S, Fischer T, Güttler T, Görlich D. Characterisation of the passive permeability barrier of nuclear pore complexes. EMBO J. 2009;28:2541-53.

61. Timney BL, Raveh B, Mironska R, Trivedi JM, Kim SJ, Russel D, et al. Simple rules for passive diffusion through the nuclear pore complex. J Cell Biol. 2016;215:57-76.

62. James P, Halladay J, Craig EA. Genomic libraries and a host strain designed for highly efficient two-hybrid selection in yeast. Genetics. 1996:144:1425-36.

63. Sherman F. [1] Getting started with yeast. In: Methods in Enzymology: Elsevier; 1991. p. 3-21. https://doi.org/10.1016/0076-6879(91)94004-V.

64. Gietz RD, Schiestl RH. High-efficiency yeast transformation using the LiAc/SS carrier DNA/PEG method. Nat Protoc. 2007;2:31-4.

65. Sikorski RS, Hieter P. A system of shuttle vectors and yeast host strains designed for efficient manipulation of DNA in Saccharomyces cerevisiae. Genetics. 1989;122:19-27.

66. Belanger KD, Walter D, Henderson TA, Yelton AL, O'Brien TG, Belanger KG, et al. Nuclear localisation is crucial for the proapoptotic activity of the HtrA-like serine protease Nma111 p. J Cell Sci. 2009;122(Pt 21):3931-41.

67. Breeden LL. Alpha-factor synchronization of budding yeast. Meth Enzymol. 1997;283:332-41.

68. Miller JH. Experiments in molecular genetics. Cold Spring Harbor, N.Y. Cold Spring Harbor Laboratory; 1972.

\section{Publisher's Note}

Springer Nature remains neutral with regard to jurisdictional claims in published maps and institutional affiliations.

Ready to submit your research? Choose BMC and benefit from:

- fast, convenient online submission

- thorough peer review by experienced researchers in your field

- rapid publication on acceptance

- support for research data, including large and complex data types

- gold Open Access which fosters wider collaboration and increased citations

- maximum visibility for your research: over $100 \mathrm{M}$ website views per year

At BMC, research is always in progress.

Learn more biomedcentral.com/submissions 